\title{
Reflexões sobre as Rodas de Conversa na Educação Infantil
}

Resumo: $O$ presente artigo apresenta reflexões sobre as rodas de conversa na Educação Infantil e busca compreender por meio de uma pesquisa de cunho qualitativo, desenvolvida a partir da análise de entrevistas semi-estruturadas, qual o sentido que três professoras da Educação Infantil da E.M.E.F Cidade do Rio Grande - CAIC/FURG atribuem às rodas de conversa e o que elas dizem sobre esse elemento do cotidiano da Educação Infantil. Num primeiro momento, dialogamos sobre a construção da ideia de infância e algumas problematizações acerca das infâncias contemporâneas. Em seguida discorremos sobre as rodas de conversa, trazendo alguns estudos de pesquisadores que analisam tal temática. Para posteriormente apresentarmos a análise da pesquisa realizada. Assim, constata-se que a roda de conversa é um elemento imprescindível que deve ser explorado pelos professores, pela sua relevância e contribuições que proporciona às crianças e ao fazer docente. Um espaço cheio de vida, de compartilhar saberes, emoções, de aprender a conversar, respeitar o outro, planejar, avaliar. Além disso, constitui-se um alicerce para a construção do novo e um espaço que também revela as pluralidades infantis.

Palavras-chave: Roda de Conversa; Infâncias; Educação Infantil

\section{Reflections about Circles of Conversation in Chil- dhood Education}

\begin{abstract}
The present work include reflections on the circle conversation in the childhood education and seeks to understand by to qualitative search, developed from to analyses of semi-structured interviews, the meaning that three teachers of the childhood education of E.M.E.F Cidade do Rio Grande - CAIC/FURG attribute the circles conversation and what they say this daily element of childhood education. So, in a first moment, I dialogue about the construction of the childhood idea and problematizations about contemporary childhood. Then, I discourse about circle conversation bringing some research studies that examine this subject. To posteriorly present the analisys of search realized. Thus, it appears that the circle of conversation is an essential element that must be explored by teachers for their relevance and contributions that provides children and teachers do. A space full of life, to share knowledge, emotions, learning to talk, respect the other, plan, evaluate. Moreover, it constitutes a foundation for the construction of a new space that also reveals the children plurality.
\end{abstract}

\section{Keywords: Circles of Conversation; Childhood; Childhood Education.}

\footnotetext{
I Mestranda no Programa de Pós-Graduação em Educação -PPGEDU da Universidade Federal do Rio Grande - FURG e professora da Rede Estadual de Ensino.E-mail: vanessaalvesvargas@gmail.com

2 Doutor em Educação pela Universidade Federal do Rio Grande do Sul (UFRGS). Professor da Universidade Federal do Rio Grande - FURG. Atua no grupo de pesquisa Crianças, Infâncias e Culturas (CIC). Editor da Revista REMEA. E-mail: vilmar1972@gmail.com

3 Doutora em Educação pela UFRGS. Professora da Universidade Federal do Rio Grande - FURG. Coordenadora do Núcleo de Estudo e Pesquisa em Educação da Infância - NEPE/FURG. E-mail: mariarenata@terra.com.br
} 


\section{Introdução}

Iniciamos a escrita deste artigo, num processo de inúmeras lembranças e reflexões vivenciadas no curso de Pedagogia, na Universidade Federal do Rio Grande - FURG e nas experiências de formação inicial no cotidiano escolar. Experenciamos a escrita desde a mais tenra idade e ainda assim verificamos frente a folha em branco que escrever não é tarefa fácil. É um processo reflexivo que exige cautela, dedicação e clareza.

Este escrever tem sido um movimento de idas e vindas, de permitir-nos ter voz, criticidade, autonomia, de reconhecer-nos como docentes e pesquisadores. Esse processo tem oportunizado, por meio do nosso pensamento que está sendo expresso na palavra escrita, estabelecer diálogos/ conversas com os leitores, desencadeando variadas reflexões e problematizações.

Significamos este momento de escrita como experiência intensa, como algo que tem tocado em nós, entendendo de fato o que Bondía (2002, p.21) quer dizer quando fala que a experiência "é o que nos passa, o que nos toca. Não o que se passa, não o que acontece, ou o que toca." Além disso, consideramos como Kohan (2005) que saímos transformados após a escrita. Isso ocorre, pelo fato desta gerar desacomodações que nos levam a refletir, questionar, bem como provocar constantes inquietações. Logo, esta escrita desencadeou vários pensares e com certeza nos levou a querer conhecer mais o tema abordado e pesquisá-lo, pois como afirma Kohan (2005, p.14) “a inquietude, posterior à experiência de escrita, multiplicou-se, aguçou-se, expandiu-se. Assim acontece com a experiência. E são as experiências que nos levaram a buscar qual o sentido que as professoras da Educação Infantil da E.M.E.F Cidade do Rio Grande - CAIC/FURG atribuem às rodas de conversa e o que elas dizem sobre esse elemento do cotidiano da Educação Infantil.

Logo, esse anseio em pesquisar sobre as rodas de conversa nasce pelo fato das rodas nos encantarem e também pelas inquietações que estas geram em nós. As rodas de conversa nos encantam na medida em que a criança tem a oportunidade de dizer sua própria palavra, da escuta dos professores, da relação dialógica que é estabelecida e por meio desta os professores perceberem as culturas, hábitos, curiosidades, interesses e/ou dúvidas que as crianças têm. Em contrapartida, as rodas de conversa nos inquietam e provocam em nós alguns questionamentos, os quais pretendemos pesquisar no presente artigo, tais como: Que espaço é esse? Qual o sentido que as professoras atri- 
buem à roda de conversa e o que elas dizem sobre esse elemento do cotidiano da Educação Infantil? Nesse sentido, pretendemos pesquisar sobre as rodas por acreditar que estas são imprescindíveis no cotidiano da Educação Infantil. Concordamos com Bombassaro (2010), quando afirma que a roda de conversa é um conteúdo-linguagem, que deve ser aprendido tanto pelas crianças quanto pelos professores e que a roda de conversa tem estruturas e regras de funcionamento.

Ademais, consideramos que é de inegável relevância os professores reconhecerem as rodas de conversa como espaço para o diálogo, momento para além de ser realizada a chamada. A roda deve ser um espaço em que todos os participantes envolvidos se expressem de fato, aprendendo a ser sujeitos críticos e atuantes, não só na escola como também na sociedade. Além disso, a roda de conversa pode ser um espaço que possibilite às crianças aprenderem a conversar.

Diante disso, no decorrer deste trabalho, apresentaremos qual o sentido que as professoras do nível II B da E.M.E.F Cidade do Rio Grande atribuem às rodas de conversa e o que elas dizem sobre esse elemento do cotidiano, por meio de um estudo de cunho qualitativo que "enfatiza o processo, aquilo que está ocorrendo, e não o produto ou os resultados finais. [...] uma pesquisa que refaz-se constantemente no próprio processo de investigação (FONTES, 2005, p.128). Com esse intuito, articulamos teoricamente as entrevistas realizadas com as professoras e apresentamos nossas percepções no que se refere às rodas de conversa, verificadas, inicialmente após algumas inserções nas rodas, conversas informais com as crianças e considerações relevantes que foram anotadas no diário de campo. Além disso, nosso convívio com esta escola e com as professoras da Educação Infantil, fez-nos perceber que a roda de conversa é um elemento bastante presente em todos os grupos de crianças deste nível educacional. Este foi um aspecto que motivou-nos ainda mais a estudar esse tema.

Para isso, seguimos a presente escrita, dialogando inicialmente sobre a construção da ideia de infância, onde tecemos algumas problematizações no que tangem aos aspectos que permeiam a infância. Procuramos evidenciar que apesar de sempre existirem crianças, por muito tempo suas vozes foram silenciadas e somente a partir do advento da Modernidade outras configurações de infância foram estabelecidas e conseqüentemente um novo lugar foi atribuído à criança.

Em seguida discorremos sobre as rodas de conversa, trazendo alguns estudos de pesquisadores que analisam tal temática, para posteriormente apresentar a análise da pesquisa realizada com 
as professoras. Assim, nosso intuito com este estudo sobre as rodas de conversa foi proporcionar variados diálogos entre estudantes e professores, a fim de refletirem e problematizarem esse elemento imprescindível do cotidiano da Educação Infantil.

\section{Breve histórico sobre a construção da ideia de infância e algumas problematizações acerca das infâncias contemporâneas.}

Nas sociedades sempre existiram crianças, porém o sentimento de infância, do reconhecimento da particularidade infantil, nem sempre existiu. Na Idade Média, como demonstram os estudos de Ariès (1981), as crianças viviam como miniadultos, participavam dos mesmos jogos, ritos, festas e atividades cotidianas dos adultos, além das suas roupas serem elementos que evidenciavam a mesma representação.

o traje da época comprova o quanto a infância era tão pouco particularizada na vida real. Assim que a criança deixava os cueiros, ou seja, a faixa de tecido que a enrolava em torno do seu corpo, ela era vestida como os outros homens e mulheres de sua condição. (ARIÈS, 198I, p.69-70)

Nesse contexto, a criança era percebida enquanto membro da família, cujo pertencimento ligava-se especialmente às tradições de seu universo de origem. (BOTO, 2002, p.22). Não havia o reconhecimento das especificidades infantis, assim as crianças ficavam num lugar subalterno em relação aos adultos. Por parte da sociedade, existia como fala Gonçalves (2004/2005, p.11) "a ideia reducionista do vir a ser, concepção bastante presente na Antiguidade, quando a criança ficava a margem da família e só era considerada sujeito quando chegava a 'idade da razão', por volta dos 15 anos. " Dessa maneira, as crianças eram marginalizadas pela sociedade adultocêntrica, a qual as considerava como futuramente adultos produtivos, "úteis" para a sociedade, sendo vistas "como meros seres biológicos, sem estatuto social nem autonomia existencial” (SARMENTO, 2002, p.3).

Nesse viés, compreendemos que havia uma invisibilidade com relação às crianças, as quais não eram reconhecidas como sujeitos no período infantil, ficando evidente que "a criança não era representada significativamente na família, estava tão somente ligada à vida do grupo como qualquer outro personagem desse contexto. " (PAULA, 2005, p.2). Isso não significa que a criança não fosse amada ou cuidada pela família, mas que existiam outras configurações da sociedade e das famílias em relação às crianças. 
Na sociedade medieval os adultos não tinham a compreensão do que Ariès (1981) intitula de sentimento de infância, ou seja, do que é especificamente infantil, por isso "assim que a criança tinha condições de viver sem a solicitude constante de sua mãe ou de sua ama, ela ingressava na sociedade dos adultos e não se distinguia mais destes.” (Ariès,1981,p.156)

Além disso, como aponta Delgado e Muller (2006,p.9) “atualmente, a produção sobre a Educação Infantil considera a infância como uma categoria social, graças ao estudo de Ariès (1981) que contribui para essa concepção.” Porém, Ariès (1981) defende a tese de que a ideia de infância surgiu a partir de dois sentimentos: a paparicação e a moralização. A paparicação, período do mimo surge no meio familiar onde os adultos "não hesitavam mais em admitir o prazer provocado pelas maneiras das crianças pequenas, o prazer de paparicá-las [...] por sua ingenuidade, gentileza e graça, se tornava uma fonte de distração e de relaxamento para o adulto" (Ariès 1981,p.158). A moralização, período moralista emerge do meio exterior à família "dos eclesiásticos ou homens da lei, raros até o século XV, e de um maior número de moralistas no século XVII, preocupados com a disciplina e a racionalidade dos costumes" com o objetivo de preservar e disciplinar as crianças. A esse respeito contraponho-nos a tal tese e, como Delgado e Muller (2006) compreendemos que há posicionamentos que excedem essa concepção apontada por Ariès:

\begin{abstract}
Especialmente nos estudos vinculados à Sociologia da Infância, como já citado estudo de Pinto (1997), encontramos posicionamentos que superam esta perspectiva. Corsaro (1997) concebe as crianças como responsáveis por suas infâncias, e portanto, elas afetam e são afetadas pela sociedade. A concepção das crianças, a partir dessa postura, corrobora a visão de infância exposta por James e Prout (1997, p.7) como "duplamente construída para as crianças e por elas". (DELGADO e MULLER, 2006, p.9)
\end{abstract}

Referente ao exposto, acreditamos que mesmo antes de ser instituída a ideia de infância as crianças vivenciavam suas experiências de infâncias de maneira singular, mas concebendo estratégias para participar de uma sociedade que não lhes atribuía um estatuto e particularidade própria. Porém, não deixavam de ser crianças, mas viviam esse momento infantil, de modo diferenciado das crianças da Contemporaneidade, devido às experiências vivenciadas na família, às culturas que estavam inseridas e pela participação em espaços exteriores ao ambiente familiar. O que não existia a essa época era um sentimento dos adultos frente às particularidades e especificidades da infância. Dessa forma, muitos anos se passaram até a sociedade valorizar a infância e compreender 
que esta fase do ciclo vital possui especificidades e diferenciações dos adultos, bem como reconhecê-la como categoria de direitos. A esse respeito Cohn (2005, p.21-22) discorre:

estudo histórico de Philippe Ariès sobre a criança e a vida familiar no Antigo Regime mostra que a idéia de infância é uma construção social e histórica do Ocidente. Ela não existe desde sempre, e o que hoje entendemos por infância foi sendo elaborado ao longo do tempo na Europa, simultaneamente com mudanças na composição familiar, nas noções de maternidade e paternidade, e no cotidiano e na vida das crianças, inclusive por sua institucionalização pela educação escolar. $\bigcirc$ que Ariès nos mostra é a construção histórica do que denomina um sentimento de infância.

Nesse sentido, o sentimento de infância, este "de preocupação e investimento da sociedade e dos adultos sobre as crianças, de criar formas de regulação da infância e da família são ideias que surgem com a Modernidade." (DELGADO, 2003, p.1). Desse modo, a ideia de infância, trouxe consigo um novo lugar proporcionado à criança, a qual passa a ser valorizada e reconhecida por suas especificidades, vista como um sujeito ativo e que possui particularidades em relação aos adultos. Logo, compreendemos conforme Sarmento (2002, p.3) que a infância construída histórica e socialmente "foi o resultado de um processo complexo de produção de representações sobre as crianças, de estruturação dos seus quotidianos e mundos de vida e, especialmente, de constituição de organizações sociais para as crianças"

Além disso, consideramos que as concepções sobre ser criança se modificaram por meio do reconhecimento da infância na Modernidade. A partir deste período "se passa a perceber a infância como algo individualizado, com necessidades específicas, marcadas pela diferenciação do mundo adulto, a criança passa a ser alvo de conhecimento.” (MOTA, 2004, p.30). Por essa razão, diversas áreas de conhecimento passaram a se interessar por questões vinculadas às crianças. Dessa maneira, “cria-se, então a necessidade de conhecer mais, saber mais sobre o sujeito criança." (MOTA, 2004, p.30). O que de fato acontece, pois constantemente estudos são produzidos por inúmeros pesquisadores interessados acerca da infância.

No contexto contemporâneo, diversos estudos têm contribuído para as compreensões acerca das infâncias e, dentre eles, é possível citarmos o campo da sociologia da infância. A partir da perspectiva adotada pela sociologia da infância, é possível compreendermos as crianças como sujeitos ativos, atores sociais, produtores de culturas, protagonistas de suas histórias e seres capazes, ou 
seja, como sujeitos-criança, os quais são ativos no processo de construção de conhecimento e que tem muito a nos dizer. Esses estudos são imprescindíveis, pois, além de ampliar nossa visão sobre a infância e ser criança, aponta caminhos metodológicos de pesquisas junto a elas. Conforme Borba (2006/2007, p.36) o campo de estudo da sociologia da infância:

\begin{abstract}
(...) vem se estruturando a partir da década de 90, em torno de alguns princípios fundamentais, sendo o principal deles a concepção de infância como uma construção social. Seu ponto de partida foi uma tentativa de romper com as visões tradicionais e biologizantes de criança, que a reduzem a um ser em devir que um dia culminará no ser adulto.
\end{abstract}

Outra questão que merece destaque refere-se à sociedade contemporânea na qual a criança está inserida. Nesta é conferida à criança um estatuto próprio, sendo reconhecida como sujeitocriança, a qual faz parte de uma categoria geracional infantil. Dessa forma, "a infância não existe como categoria estática, como algo sempre igual. A infância é algo que está em permanente construção. " (Arroyo,1994, p. 88)

$\mathrm{Na}$ atual sociedade, da qual a criança faz parte, vive-se um tempo de inúmeras mudanças, tais como: tecnológicas, climáticas e relacionais, em que o ter, muitas vezes, sobrepõe-se ao ser. Vivemos um tempo do imediatismo, em que as pessoas não param, ficando constantemente atribuídas de diversas funções. Não raro, percebe-se que a individualidade e a inversão de valores estão acentuadas, bem como a provisoriedade que as pessoas atribuem aos objetos, e infelizmente também as pessoas. Como fala Tfouni e Silva (2008, p. 177) “a nossa cultura é a do lixo, do descartável imediatamente, sem causar grandes transtornos". Isso tudo vai ao encontro de que a descartabilidade "é característica dos seres humanos e das relações que estabelecem, obedecendo à máxima da sociedade em que estamos inseridos: o consumir" (TFOUNI e SILVA, 2008, p. 177).

Além disso, considero como o sociólogo Zygmunt Bauman, que vivemos num tempo da modernidade líquida. Onde, "a duração deixa de ser um recurso para tornar-se um risco; o mesmo pode ser dito de tudo que é volumoso, sólido e pesado - tudo que impede ou restringe o movimento” (BAUMAM, 2001, p.148). Pertinente a essa questão saliento Tfouni e Silva (2008) discorrem: 
lonês, faz com que as instituições sociais percam a solidez e se liquefaçam, tornando-se amorfas, paradoxalmente, como os líquidos. A modernidade líquida, assim, é tempo do desapego, provisoriedade e do processo da individualização; tempo de liberdade ao mesmo tempo em que é o da insegurança. (TFOUNI, SILVA, 2008,p. I76)

Isso tudo se consolida devido o modo de viver do século XXI, o qual apresenta outras configurações na maneira de experienciar a vida e conseqüentemente a infância. Nesse tempo em que vivemos, todos estão atribuídos de inúmeras funções cotidianas, constantemente com pressa, e por vezes, nem há tempo de sentir a vida passar.

Além do exposto, considero que "reunir-se para falar é um dos atos mais característicos e saudáveis que acontece entre as pessoas. Mas, neste tempo de urgências, de "para ontem", de "eficácia”, isto está se transformando num costume frágil (NAVARRO, 2004). As pessoas, em virtude da vida "corrida" não estão disponíveis a escutar o outro, ouvir o que ele tem a dizer, e quando o fazem, constantemente utilizam-se de instrumentos tecnológicos que contribuem para a comunicação.

A esse respeito Bombassaro (2010, p.9) ressalta que:

\begin{abstract}
Hoje vivemos numa sociedade onde nunca se conversou tanto, ao menos pela internet e pelo telefone. Em contrapartida, quando os sujeitos se encontram presencialmente, há um vazio muito grande, ao que parece, sabemos conversar sim, desde que intermediados pela tecnologia. Frente a frente, corpo a corpo, face a face, poucos sabem, poucos se sentem à vontade. Na vida em família, o tempo é curto. As crianças passam o dia na escola, desde bem pequenos, e em casa, no pouco tempo que passam com seus familiares, muitas vezes, o que chega pela boca do adulto no lugar da conversa é a prescrição.
\end{abstract}

Diante disso, na atual sociedade em que todos estão atribuídos de diversas atividades, que espaços têm sido destinados a escuta das crianças? Em que suas vozes, de fato, sejam ouvidas? É isto que pretendemos discorrer a seguir. Com isso, não estamos querendo afirmar que as crianças só aprendem a conversar e só podem ser ouvidas nas rodas de conversa na escola, mas que esta constitui-se de extremo valor para que elas tornem-se sujeitos críticos, criativos, posicionando-se criticamente nos mais diversos assuntos. Nesse sentido, compreendemos a roda como: 
as outras. Mas o que quero ressaltar é que crianças e os adultos, quando se encontram na escola, em especial na Roda, podem se tornar grandes parceiros, grandes interlocutores à altura uns dos outros, para dialogarem, conversarem e, juntos, conhecerem sobre si, sobre o outro e sobre o mundo (...) (BOMBASSARO, 2010, p.9)

Portanto, na próxima seção seguimos nossa conversa, partindo para a discussão da roda de conversa como um ambiente de conhecimento, aprendizagem, diálogo e, sobretudo de vida!

\section{Rodas de conversa: que espaço é esse?}

Bombassaro (2010), em sua pesquisa sobre as rodas de conversa na Educação Infantil, aponta que há muito tempo as rodas de conversa fazem parte da história de muitas sociedades. Basicamente, nas rodas de conversas, desde os tempos mais remotos, as pessoas reuniam-se para compartilhar saberes cotidianos, tradições, bem como histórias, as quais iam sendo passadas de geração em geração. Dessa forma, reunir-se para conversar em roda é uma prática social que existe há muito tempo, e que proporciona diversas aprendizagens. Como diz Bombassaro (2010, p.9) promove "conhecimentos sobre si, sobre o outro e sobre o mundo.” Reunir-se numa roda de conversa, pode proporcionar a interação entre os pares e inúmeros saberes, partilhados e ressignificados a partir das discussões.

$\mathrm{Na}$ Educação Infantil não é diferente, as rodas de conversa oportunizam também o aprender a conversar, o falar, o saber ouvir, a reflexividade e, sobretudo, impulsiona a criticidade, a argumentação e o diálogo. Os participantes da roda aprendem a exercer a escuta ao outro, a ouvir de forma respeitosa as hipóteses, conhecimentos e vivências que o outro fala ao grupo. Nesse sentido, compreendemos a escuta, como Rinaldi apud Ostetto (2000) ao dizer que "a escuta é disponibilidade ao outro e a tudo quanto ele tem a dizer; é escuta das cem e mais linguagens com todos os sentidos".

A escuta nas rodas de conversa, constitui-se algo que estimula as crianças a reconhecerem a existência do outro e que este possui, por vezes, ideias compatíveis com as suas e também formas de pensar antagônicas. Dessa forma, acreditamos como Warschauer (1993, p.46) que as Rodas de conversa caracterizam-se por: 
reunir indivíduos com histórias de vida diferentes e maneiras próprias de pensar e sentir, de modo que os diálogos, nascidos desse encontro, não obedecem a uma mesma lógica. São às vezes atravessados pelos diferentes significados que um tema desperta em cada participante.

Logo, os diálogos, oportunizados nas rodas de conversa são muito relevantes, pois a partir deles as crianças organizam suas ideias para expressá-las e problematizá-las. Isso ocorre num processo de mudança de opinião, criação de novas hipóteses, defesa de ideias, além da reflexão sobre diversos temas trazidos pelas crianças durante as rodas, visto que a abertura ao novo é a primeira característica da roda (WARSCHAUER,1993, p.48). Um novo assunto pode ser desencadeado por algum participante da roda e vai sendo discutido por todos que dela fazem parte. São falas que geram conversas, diálogos e reflexões! Barbosa e Horn (2008, p.121) afirmam que as crianças:

ao conversarem em pequenos e grandes grupos nos quais as idéias voltam, voam alto ou se diluem. $O$ conhecimento chega-lhes através de conversas, de diálogos e de discussões [...] em um processo de reflexão contínuo entre as crianças.

Além disso, durante as rodas de conversa as crianças têm a liberdade de expressarem o que lhes é significativo, o que lhes emociona, inquieta, causa dúvida, tem curiosidade. Ou seja, a roda de conversa é um elemento cotidiano da rotina que proporciona o compartilhar de saberes, experiências, alegrias, tristezas, num processo de diálogo e aprendizagem que envolve a fala e a escuta ao outro. Sendo que "a Roda é uma construção própria de cada grupo [...] em que ocorre a interação entre os participantes [...] sob a organização do coordenador, o professor, por exemplo. " (WARSCHAUER,1993, p.47).

A roda de conversa, elemento imprescindível do cotidiano da Educação Infantil, é esse momento de encontro, de partilha, de conhecimento, aprendizagens, um espaço que "se aprende a conversar, porque a Roda é de conversa e não para preencher o tempo precioso desse encontro igualmente precioso entre o professor e as crianças (...)" (BOMBASSARO, 2010, p.7). Considero que os professores devem realizar juntamente com as crianças as rodas como espaço para conversa, tendo um olhar e escuta observadora as vozes das crianças, não desperdiçando ou suprimindo esse encontro tão valioso. Defendo as rodas de conversa numa perspectiva considerada por Bombassaro (2010, p.8) a qual concebe as rodas "como um conteúdo-linguagem a ser ensinado e aprendido na 
educação infantil, na perspectiva apontada por Junqueira Filho (2005), que busca em Charles Sander Peirce o conceito de linguagem. " Sobre tal perspectiva Bombassaro (2010, p.25), discorre:

Para Peirce (apud JUNQUEIRA FILHO,2005), linguagem é toda e qualquer produção, realização e funcionamento do homem e da natureza; cada linguagem tem estrutura e regras próprias de funcionamento a partir das quais pode ser aprendida e continuar a ser produzida, como é o caso da Roda, produção, realização, funcionamento humano que é. A partir dessa concepção de linguagem Junqueira Filho (2005) elabora uma concepção de conteúdo, aplicada à escola infantil, significando conteúdo como linguagem -conteúdo-linguagem- ou seja, conteúdo como toda e qualquer produção, realização, funcionamento

do homem e da natureza.

Nesse encontro da Roda, em que as crianças também aprendem a conversar são desencadeados inúmeros pensares e reflexões nos pequenos a partir das discussões suscitadas nesse espaço de encontro. Acredito como Benjamim apud Corsino,(2009) que por meio da narrativa as crianças vão se expressando e compartilhando com o grupo suas experiências, além de criarem laços de afetividade. De acordo com Corsino (2009, p.63):

A narrativa é considerada por Benjamim (1993 a) um espaço fundamental de intercâmbio de experiências. É narrando para o outro o que nos aconteceu que as vivências dos fatos perde a finitude do presente e ganha uma nova dimensão, pela possibilidade de continuidade do ouvinte. Criamos laços com o outro quando podemos falar e ouvir, quando nos colocamos e nos vemos no lugar do outro, partilhando as experiências vividas.

Também consideramos, que pela vivência com o grupo cria-se um ambiente em que os participantes da roda se sentem à vontade para conversar, num movimento contínuo que as crianças que anteriormente não se autorizavam a expressar-se passam a fazê-lo. Warschauer (1993,p.46) discorre que "a constância dos encontros propicia um maior entrelaçamento dos significados individuais, a interação aumenta e criam-se significados comuns, as vezes até uma linguagem própria.” Ou seja, característica dos participantes da roda de determinado grupo, justamente pela convivência grupal.

A roda de conversa, se constitui num espaço encantador, em que a relação dialógica acontece entre crianças-crianças, crianças-professor(a). Nesse viés, acreditamos como Junqueira Filho, apud Bombassaro (2010, p.31) que "as crianças podem ser interlocutoras à altura dos adultos e com estes constituírem uma relação de parceria.” Diante disso, compreendemos que as crianças têm mui- 
to a nos dizer, e possuem muitos saberes que merecem ser ouvidos, pois a criança não sabe menos que o adulto ela sabe outras coisas (COHN, 2005).

Assim, a roda de conversa é este elemento imprescindível que deve ser explorado pelos professores, pela sua relevância e contribuições que proporciona às crianças e ao fazer docente. Um espaço cheio de vida, de compartilhar saberes, emoções, de aprender a conversar, respeitar o outro, de planejar, avaliar, alicerce para a construção do novo e um espaço que também revela as pluralidades infantis.

\section{As rodas de conversa no cotidiano da Educação Infantil da escola situada no CAIC/FURG}

Para entender como as rodas de conversa tem sido empregadas no ambiente escolar, realizamos uma pesquisa de cunho qualitativo a partir de entrevistas semi-estruturadas com três professoras da Educação Infantil, que serão nominadas como professoras A, B e C. Tal entrevista foi gravada em áudio digital e posteriormente transcrita e analisada. A entrevista abordou três aspectos principais:

1. Como se dá a organização das rodas de conversa?

2. Qual a importância da roda de conversa no ambiente escolar e o sentido de realizá-las?

3. Quais as contribuições da roda de conversa no cotidiano educativo da Educação Infantil?

A seguir estaremos articulando teoricamente as falas das professoras e suas contribuições sobre cada aspecto investigado.

\section{Como se dá a organização das rodas de conversa?}

A organização das rodas de conversa para essas professoras parece não obedecer a um padrão definitivo, a qual nos remete pensar que cada professora utiliza um método próprio e particular na condução dessa prática cotidiana da Educação Infantil. Nesse viés, apresentamos algumas falas das professoras quando perguntadas sobre as formas de organização da roda de conversa: 
vezes ela acontece no pátio, não tem uma regra de ser em um determinado lugar." "E às vezes (...) já tenho uma história do dia anterior que eu achei que fosse necessária contar logo no começo, ai eu já preparo todo aquele clima pra roda da leitura da história acontecer no começo ou uma novidade ou algum recado, ou alguma conversa que eu quero ter com eles logo no começo ai eu já preparo pra ser naquele momento, na entrada.(...) Outras vezes acontece de a criança já vem contando alguma coisa no caminho da entrada até a nossa sala, ai a roda é realizada no começo. (PROFESSORA A)

Faço todos os dias, geralmente eu faço na entrada, no momento que eles entram eles largam as mochilas, e eles já sentam na rodinha, eles já sabem que tem que sentar porque aquele momento é pra gente conversar....) "Às vezes acontece dentro da sala de aula, no espaço da sala no tapete, às vezes quando eu vou levá-los no pátio, ai depende do dia. (PROFESSORA B)

Na verdade não precisa ter um momento específico, mas ai a gente sempre faz na entrada, porque eles já se organizam, na entrada, e até é mais interessante, porque dali já surge o resto da tarde. (PROFESSORA C)

A partir da análise das falas das entrevistadas é possível analisar que as professoras A e B não atribuem um espaço físico na condução das rodas de conversa, realizando-as em diversos lugares do ambiente escolar. Em contrapartida, a professora $C$ realiza as rodas de conversa apenas no espaço da sala.

Segundo as entrevistas a roda de conversa se apresenta em diferentes instantes. A professora A comenta que a roda não se restringe a um momento específico dos encontros, deixando assim que ela surja de forma espontânea. Por outro lado, as professoras B e C consideram que a roda no momento inicial, propicia uma melhor organização do ambiente educativo das suas turmas.

Um outro fato bem interessante a ser mencionado se caracteriza ao assunto da roda de conversa. A professora A comenta que a roda de conversa de sua turma não se limita a assuntos previamente estabelecidos, mas também pela liberdade das crianças expressarem seus sentimentos e percepções sobre assuntos que as tocam e inquietam.

Diante das falas das professoras compreendo que “(...) a roda é uma construção própria de cada grupo" (WARSCHAUER, 1993, p. 47), desta forma consideramos que cada turma deve, com sua professora, estabelecer um ambiente adequado para a realização da roda de conversa. Ambiente este, que se caracteriza pela liberdade de expressão oral e corporal, não restringindo-se a um espaço físico e temporal.

Sobre a organização do grupo de crianças na roda de conversa a professora $C$ ressalta: 
Eles se organizam ali na roda, alguns preferem sentar nas cadeiras, outros se deitam, outros não tão muito afim ai ficam meio emburrados num canto, e ai a gente não força, mas aos poucos eles se inserem na conversa.

Colaborando com este pensamento, Bombassaro (2010, p. 44) comenta que: “cada grupo de crianças com sua professora vão construir um jeito de organizar-se física e espacialmente na Roda, ser Roda, estar em Roda, funcionar na Roda." Sendo assim, cada grupo de crianças tem a liberdade de construir de forma singular a sua Roda. Além disso, Bombassaro (2010, p. 45) diz também que:

As crianças podem ficar à vontade e ocupar o espaço corporalmente a partir de diferentes modos - ora deitado, ora sentado, ora escorado na professora, ora deitado ou sentado numa almofada - desde que esse jeito não atrapalhe o funcionamento do grupo como um todo.

Sendo assim a roda de conversa deve ser estabelecida de forma singular e especifica em cada grupo, motivando-os a socializarem o que consideram relevante e conhecerem a si próprios e ao outro.

Qual a importância da roda de conversa no ambiente escolar e o sentido de realizá-las?

Nessa questão, constata-se que cada professora confere sentidos particulares às rodas de conversa em sua ação docente. A Professora A não estipula uma única importância às rodas de conversa, ela a compreende como uma prática muito relevante a qual promove a acolhida, a escuta ao outro e sendo também um instrumento democrático, que promove inúmeras aprendizagens e conhecimentos. Além disso, a considera um elemento importante que contribui para a realização do seu planejamento. Desse modo, ela compreende a roda como um espaço de possibilidades.

Eu acho a roda assim, ela não tem uma única importância, acho que na Educação Infantil, ela é muito boa em tudo, ela é muito boa pra acolher, muito boa pra ouvir, ela é democrática, e onde sai as sugestões, onde sai as ideias, onde eu consigo planejar. (PROFESSORA A)

E nesse ambiente de conversa, de conhecimento, de encontro, de revelação dos anseios e saberes das crianças, as professoras têm a possibilidade de desenvolver planejamentos que atendam 
aos desejos e curiosidades das crianças.

Além disso, é nas rodas que a professora e as crianças avaliam os projetos e/ou atividades que estão desenvolvendo e o próprio processo vivenciado com os colegas e a professora. E isso pode contribuir para um ambiente educativo humanizador e que promove o desenvolvimento integral das crianças.

Já as Professoras B e C significam as rodas como um espaço importante que oportuniza às crianças expressarem seus desejos, lembranças, dificuldades, inquietações e alegrias. A professora B, ainda salienta que através da Roda, tem a oportunidade de conhecer a turma e cada criança em particular, pelo fato de desenvolver sua sensibilidade e apurar sua escuta às crianças.

Sobre a importância das rodas e o sentido de realizá-las as professoras B e C discorrem:

\begin{abstract}
Eu faço a Roda até mesmo pra conhecer cada um deles, conhecer a turma, até porque nos momentos da roda é um momento que eles podem colocar as opiniões deles, que a gente pode estar conhecendo um pouco mais sobre cada um, as vontades, eles manifestam os desejos, até mesmo com relação as dificuldades. (PROFESSORA B)
\end{abstract}

Acho importante porque é o momento deles se expressarem, e eles querem contar, contar, o que fizeram, o que comeram o que gostam, o que não gostam, é o momento que eles têm pra se expressarem. (PROFESSORA C)

Logo, consideramos que a roda de conversa propicia inúmeras aprendizagens e conhecimentos para todos os participantes que a colocam em funcionamento. Um momento de criar, recordar, pensar/repensar e reviver momentos vivenciados. E na escola em questão, percebemos a partir das inserções nas turmas de Educação Infantil, que isso ocorre em um ambiente em que todos podem se olhar, entrar em comunicação por meio de diferentes linguagens. A partir de tais considerações, pensamos que a roda de conversa é uma ferramenta de inegável relevância para o fazer docente, pois oportuniza as professoras, entre outros aspectos, conhecer a turma, cada criança em particular e apurar sua escuta e olhar observador as manifestações das crianças.

\title{
Quais as contribuições da roda de conversa na Educação Infantil?
}

No sentido de conhecer quais as contribuições que as professoras atribuem às rodas de conversa, foi realizada a seguinte pergunta: Quais as contribuições da roda de conversa na Educação 
Infantil? Apresento, a fala da professora A no que tange a esta pergunta:

\begin{abstract}
Acho a roda de conversa em todos os momentos muito boa, não só na Educação Infantil, no primeiro ano, e nos outros anos deveria acontecer. Fora da escola eu também acho muito boa, é algo que aproxima, que tu consegue ouvir o outro, consegue colocar as tuas ideias, às vezes não só com palavras, mas as vezes tem aquela criança que não fala nada, mas ta ali na roda de conversa e tu vê se ela ta prestando atenção, ou se o olhar dela tá no outro lugar, se ela ta brincando com o colega, ai tu consegue vê, analisar, avaliar o comportamento da criança naquele momento da escuta, da conversa, da acolhida do outro, acho bem legal. A roda de conversa é algo bem produtivo, sai tudo da roda de conversa, tudo tu consegues tirar, é claro que sai em outros momentos, eles brincando sai várias ideias, sai sugestões, sai também em outros momentos. Mas acho que na roda, é um lugar onde tem mais criação, tem mais nesse momento, acho também até mesmo porque é o momento da acolhida, da aproximação (...) (PROFESSORA A).
\end{abstract}

A professora A, percebe que a roda de conversa é muito importante não só na Educação Infantil, mas também nos demais anos do Ensino Fundamental e também em espaços exteriores ao ambiente escolar. Compreende a roda como uma prática que aproxima as pessoas, momento de escuta ao outro, de expressar ideias e sugestões. Ela considera a roda como uma prática muito produtiva, lugar de conhecer e acolher o outro, evidenciar os desejos, as sugestões do grupo e também um lugar onde há mais criação, justamente pelo fato da acolhida e aproximação do outro.

Outra questão apontada pela Professora A é a sua percepção sobre as crianças que não falam nos momentos da roda. A entrevistada analisa que tais crianças se expressam de outras maneiras: por meio de um olhar, um gesto, expressões e assim a professora consegue ver, avaliar e analisar o comportamento da criança naquele momento da roda.

Corroborando com essa questão trago as contribuições de Bombassaro (2010,p.51) quando fala que nas rodas as crianças tem a liberdade também de ficarem em silêncio, "mas provocadas pelo o que está sendo dito”. Sobre essa questão ela discorre:

(...) mesmo aquelas que não desejam entrar verbalmente na conversa têm o direito de participar dela, prestando atenção apenas e não falar; e isto é garantido pela professora, fazendo parte da estrutura e das regras de funcionamento da Roda. [...] o silêncio também é uma forma de conversa, de entrar, de estar na conversa. Talvez uma criança esteja em silêncio porque está pensando sobre o que está ouvindo. E pode continuar em silêncio mesmo depois que já tenha uma posição sobre o que estava pensando em silêncio. Não conversar verbalmente na Roda não significa que não esteja conversando na Roda.

Ainda, a esse respeito, acredito que se faz necessário os professores respeitarem as crianças e não obrigá-las a expressarem-se verbalmente, mas propiciar um ambiente de acolhida as suas manifestações, lembrando que merecem atenção e respeito não somente as crianças falantes, mas 
também as crianças que estão silenciosas. Nesse sentido, entendo que "as crianças que estão em silêncio estão acompanhando intensamente as conversas em andamento; no entanto preferem não se pronunciar verbalmente e este é também um funcionamento possível dos participantes da Roda" (BOMBASSARO, 2010,p.51).

A Professora B concebe as rodas como um momento enriquecedor tanto para a professora, que pode constatar os anseios e inquietações do grupo, quanto para as crianças que tem a liberdade de expressar seus sentimentos e experiências vivenciadas na escola ou em espaços exteriores a ela. A esse respeito friso a fala da entrevistada B:

\begin{abstract}
A rodas, são fundamentais até mesmo pra proposta da professora, porque ela auxilia, é uma ferramenta.[...] Eu acredito que a roda seja um momento enriquecedor, assim, porque além das manifestações deles, é o momento que eles têm pra colocar aquilo que eles tão sentindo, o que acontece com eles em casa, tudo que vem acontecendo eles tem a oportunidade de colocar naquele momento ali, que é deles, a roda. Não que em outros momentos eles não possam fazer isso, mas eu acredito que seja o momento que eles tem juntos, pra exporem o que eles estão sentindo, e pra professora ir conhecendo a turma.
\end{abstract}

Pertinente a isso, consideramos conforme Warschauer (1993,p.66) que a Roda de conversa é "um momento privilegiado da rotina para a "leitura" dos desejos e das necessidades" que as crianças estão apresentando. Tal autora discorre que em sua prática docente a roda de conversa constituía-se imprescindível, pois como ela mesma fala era na roda que avaliava e planejava o encaminhamento das atividades junto às crianças, "reconstruindo a própria rotina, quando necessário." (WARSCHAUER, 1993, p.66).

Acreditamos também, que a receptividade do grupo ao que a criança está dizendo é um fator determinante para a mesma falar ou calar-se. Se esta sentir-se reprimida pelos colegas e/ou pelo (a) professor(a) não se autorizará a comunicar-se. Porém se sentir-se acolhida, falará e desenvolverá sua argumentação e criticidade. Logo, num ambiente de respeito aos colegas, de acolhidas às suas falas, cada participante da roda dispostos "de forma que todos se vejam, em círculo, já é um convite a querer falar e ouvir." (WARSCHAUER,1993,p.50). E neste conversar acontece um movimento que "as crianças podem ir aprendendo umas com as outras, vendo-se reagir diante do que vai acontecendo, ouvindo-se opinar, observando-se...” (NAVARRO, 2004, p.197). Isso lhes garante autonomia num processo em que vão se autorizando a falar. 
Em consonância com essa questão trago a fala da professora B:

(...) se tu analisar assim desde o início até o final do ano, nas rodas eles vão mudando, vão se soltando mais, e isso é visível. Tem crianças que no início ficam mais presas, retraídas, não querem falar, e ai conforme vai indo, o coleguinha ele fala, o outro já se solta mais, ele fala mais um pouco. (PROFESSORA B)

Isso nos mostra que as crianças na medida em que vão participando das rodas e conseqüentemente a colocando em funcionamento vão descobrindo o que é a roda de conversa. Vendo o colega falar, aos poucos vão autorizando-se também a comunicar-se por meio da acolhida do grupo. Acolhida não só porque a professora disse para ouvir e respeitar os colegas, mas por cada participante da roda verificar que:

(...) aquilo que está sendo dito é importante, seja para o falante, seja para o ouvinte, porque faz parte do jeito como aquele sujeito que está com a palavra pensa e sente; porque falar pode ajudá-lo a se ouvir e a se pensar de outro modo; porque ouvir os demais, pode quem sabe, pensar de outro modo o que acabou de dizer (...) (BOMABASSARO, 20I0, p.50)

Já a Professora C acredita que as rodas contribuem para os professores perceberem as concepções e percepções que as crianças têm e estão construindo sobre o outro, sobre o mundo, sobre si próprio, e até mesmo sobre o trabalho da sua professora.

\begin{abstract}
Ali é o momento que a gente nota as concepções deles, as percepções, o que eles estão construindo sobre o mundo, até sobre o meu próprio trabalho, a atividade com eles. A gente vê, eles falam o que a gente tinha feito com eles há um tempo atrás e isso reflete lá na roda. Quando eles formulam uma frase, quando eles formulam um conceito, quando surge alguma conversa sobre o mundinho que a gente vinha trabalhando. Então eles largam umas frases que a gente vê que é importante, ali que eles constroem as ideias deles, deles se expressarem. Claro, que às vezes em casa eles devem conversar, com a mãe, mas ali eles sabem que o momento é deles, deles conversarem com os amigos, de se expressarem. (PROFESSORA C)
\end{abstract}

Além disso, a entrevistada C, compreende que a roda de conversa propicia as crianças construírem suas ideias num ambiente em que o grupo coloca a roda em funcionamento. Desse modo, “as crianças expressam o que pensam e se posicionam, argumentando não só com a professora, mas entre elas.” (BOMBASSARO, 2010, p.50) 
Assim, por meio das falas das professoras entrevistadas e dos estudos teóricos estudados compreendemos a roda de conversa como um momento de encontro entre crianças-crianças, crianças-professora, em que os sujeitos entram em comunicação através das diferentes linguagens.

\section{Considerações Finais}

É preciso conversar para aprender a entender, compreender o outro, e dessa forma, a si mesmo. Também na conversa é necessário aprender a calar para ouvir, prestando atenção no que os outros têm a dizer, para depois contribuir com as suas próprias falas no diálogo. FLORES (2010, p. I3)

Nessa seção destacamos o prazer de ter realizado o curso de Pedagogia e participado de inúmeras rodas de conversa e de discussões com docentes e estudantes, nas quais tivemos a oportunidade de "conversar para aprender, calar para ouvir e prestar atenção nas falas do outro para depois contribuir com minhas falas no diálogo". (FLORES, 2010,p.13) Nessas diversas conversas várias problematizações aconteceram e dentre elas, a temática em destaque: o estudo acerca das infâncias. Compreender que a infância não é homogênea e universal, mas um modo particular de cada criança experenciá-la.

A partir disso, constatamos com maior veemência a importância da roda de conversa e o quanto ela é imprescindível ao fazer docente. Um espaço de vida, de descoberta, partilha, criação, acolhida e se bem utilizado, esse modo tão particular de aprendizado, promove inúmeros saberes e, sobretudo a ACOLHIDA e ESCUTA ao outro.

Antigamente era corriqueiro que as famílias se reunissem ao entorno da mesa na hora das refeições, e ali exerciam a prática das rodas de conversa. Através dela muitas histórias eram contadas, culturas eram passadas para as próximas gerações, vitórias eram compartilhadas. Hoje em dia com o mundo voltado ao imediatismo essa prática social vem cada vez mais deixando de ser exercitada nas famílias. O mundo virtual através de sites de relacionamentos vem ocupando este espaço de escuta em que cada pessoa necessita como ser humano, o espaço de falar e ouvir. Desta forma, os relacionamentos tornam-se cada vez mais superficiais e o elo familiar e fraterno é sucumbido pelo modo de vida que não preenche as expectativas humanas. Isso tudo nos revela que as Rodas de conversa devem ser diariamente exercidas no seio familiar, onde pais e filhos, através das rodas, expõem seus 
anseios, frustrações, medos e expectativas.

Todos nós temos o anseio de viver em sociedade e para que isso aconteça a prática das rodas de conversa deve ser exercida. As relações virtuais não podem superar as que ocorrem de forma presencial. $\mathrm{Na}$ escola isso também não pode ser esquecido. $\mathrm{O}$ professor enquanto mediador do conhecimento deve apurar sua escuta às crianças, pois é através dessa escuta que o aprendizado se fundamenta e o ambiente escolar se torna cada dia mais interessante e prazeroso.

Logo, participando do cotidiano da escola, do convívio com as crianças colocando em funcionamento inúmeras rodas de conversa e desenvolvendo este estudo, nos sentimos cada vez mais instigados a continuar pesquisando este tema, mas agora, a partir da percepção das próprias crianças.

Por fim gostaríamos de agradecer a sua ESCUTA, pois através deste artigo realizamos um momento de conversa que não se caracteriza pela oralidade, mas como uma das mais belas formas de comunicação: a escrita. E por acreditarmos que aprendemos muito quando escutamos o outro, encerramos este trabalho desejando que os nossos ouvidos se abram a cada dia para que o outro tenha vez e voz.

\section{Referências}

ARIÈS, Philippe. A História Social da Infância e da Família. Rio de Janeiro: Zahar, 1981

ARROYO, Miguel Gonzales. O significado da Infância. In: Simpósio Nacional de Educaçáo Infantil. Brasília, 1994.

ARROYO, Miguel. Ofício de mestre: imagens e auto-imagens. $8^{\mathrm{a}}$ ed. Petrópolis, RJ: Vozes, 2000.

BARBOSA, Maria Carmen Silveira. Culturas e processos de socialização das crianças pequenas. Pátio - Educaçáo Infantil. Ano V n ${ }^{\circ}$ 15, 6-9, NOV 2007/FEV2008.

BARBOSA, Maria Carmen Silveira; HORN, Maria da Graça Souza. Projetos Pedagógicos na educaçáo infantil. Porto Alegre: Artmed, 2008.

BAUMAN, Zygmunt. Espaço Plural Zygmunt Bauman: Entrevista sobre a Educação. Desafios Pedagógicos e Modernidade Líquida. Cadernos de Pesquisa, v. 39, n. 137, p.661-683, maio/ago. 2009.

BAUMAN, Zygmunt. Modernidade Líquida. Rio de Janeiro: Jorge Zahar Ed, 2001.

BOMBASSARO, Maria Cláudia. A Roda na Educaçáo Infantil: Aprendendo a Roda aprendendo a conversar. 2010. 96f. Dissertação (Mestrado) - Faculdade de Educação. Universidade Federal do Rio Grande do Sul, Porto Alegre. 
BONDÍA, Jorge Larrosa. Notas sobre a experiência e o saber de experiência. Revista Brasileira de Educaçáo, no19, 20-28, Jan/Fev/Mar/Abr, 2002.

BORBA, Angela Meyer. Culturas da infância nos espaços-tempos do brincar: Estratégias de participação e construção da ordem social em um grupo de crianças de 4-6 anos. Momento, Rio Grande, 18: 35-50, 2006/2007.

BOTO, Carlota. capítulo O desencantamento da criança: entre a Renascença e o Século das Luzes. In: FREITAS, Marcos Cezar de; KUHLMANN, Moysés Jr. (orgs.). Os intelectuais da Infância. São Paulo: Cortez, 2002. p.11-60

COHN, Clarice. Antropologia da criança. Rio de Janeiro: Jorge Zahar Ed.,2005.

CORSINO, Patrícia. (org). Educação infantil: Cotidiano e políticas. Campinas, SP: Autires Associados, 2009. (coleção educação contemporânea)

DELGADO, Ana Cristina Coll e MULLER, Fernanda. Apresentação: Tempos e Espaços das Infâncias. Currículo sem Fronteiras, v.6,n.1,p.5-14,Jan/Jun 2006

DELGADO, Ana Cristina Coll. Infâncias e Crianças: O que nós adultos sabemos sobre elas? Rio Grande do Sul, 2003(mimeo).

DELGADO, Ana Cristina Coll; MOTA, Maria Renata Alonso; ALBUQUERQUE, Simone Santos de; (Orgs). Tempos e lugares das infâncias: educaçáo infantil em debate. Porto Alegre: IPPOA - Instituto Popular Porto Alegre, 2004. 148p.

FLORES, Sabrina Bezerra, Roda de Conversa e resoluçáo de conflitos na Educaçáo Infantil. Disponível em: <http://www.lume.ufrgs.br/bitstream/handle/10183/27401/000764732.pdf?sequence $=1>$ Acesso em: 18/11/11

FONTES, Rejane de S. A escuta pedagogia à criança hospitalizada: discutindo o papel da educação no hospital. Revista Brasileira de Educaçáo. No 29, 119-138, 2005, p.128, Maio/Jun/Jul/ Ago, 2005

GONÇALVES, Ana do Carmo Goulart. Contextualização da Infância no Espaço Urbano: os possíveis efeitos da globalizaçáo. Momento, Rio Grande, 17: 11-18, 2004/2005.

KOHAN, Walter Omar. Infância. Entre educaçáo e filosofia. Belo Horizonte: Autêntica, 2005.

MOTA, Maria Renata Alonso. A cultura Lúdica na Infância. In: DELGADO, Ana Cristina Coll; MOTA, Maria Renata Alonso; ALBUQUERQUE, Simone Santos de; (org). Tempos e lugares das infâncias: educaçáo infantil em debate - Porto Alegre: IPPOA - Instituto Popular Porto Alegre, 2004. 148p.

NAVARro, M. Carmen Díez. Afetos e emoçóes no dia-a-dia da educaçáo infantil. Porto Alegre, Artmed, 2004.

NOGUEIRA, Gabriela Medeiros. Crianças construindo a noção de passado e presente através da fotografia. In: DELGADO, Ana Cristina Coll; MOTA, Maria Renata Alonso; ALBUQUERQUE, Simone Santos de; (org). Tempos e lugares das infâncias: educaçáo infantil em debate - Porto Alegre: IPPOA - Instituto Popular Porto Alegre, 2004. 148p.

OSTETTO, Luciana Esmeralda (org.). Encontros e encantamentos na educação infantil: Partilhando experiências de estágios. Campinas, SP: Papirus, 2000. p.175-199.

PAULA, Elaine de. Crianças e Infâncias: Universos a Desvendar. Disponível em: < ced.ufsc. 
br/-zeroseis/elaine.doc> Acesso em: 18/09/11.

SARMENTO, Manuel Jacinto. As Culturas da Infância nas Encruzilhadas da Segunda Modernidade. In: SARMENTO, Manuel Jacinto, CERISARA, Ana Beatriz. Crianças e Miúdos. Portugal: ASA, 2002.

TFOUNI, Fabio Elias Verdiani e SILVA, Nilce de. A modernidade líquida: o sujeito e a interface com o fantasma. Disponível em: < http://pepsic.bvsalud.org/pdf/malestar/v8n1/09.pdf > Acesso em: 19/06/2011

WARSCHAUER, Cecília. A roda e o registro: uma parceria entre professor, alunos e conhecimento. Rio de Janeiro: Paz e Terra, 1993. 